\title{
Efficacy of a Web-Based Self-Management Enhancing Program for Patients with Rheumatoid Arthritis: Explorative Randomized Controlled Trial
}

Rixt Zuidema ${ }^{1}$, MSc; Sandra van Dulmen ${ }^{2,3,4}, \mathrm{PhD}$; Maria Nijhuis-van der Sanden ${ }^{1}, \mathrm{PhD}$; Inger Meek ${ }^{5}$, PhD; Cornelia van den Ende ${ }^{6}$, PhD; Jaap Fransen ${ }^{5}$, PhD; Betsie van Gaal ${ }^{1,7}, \mathrm{RN}, \mathrm{PhD}$

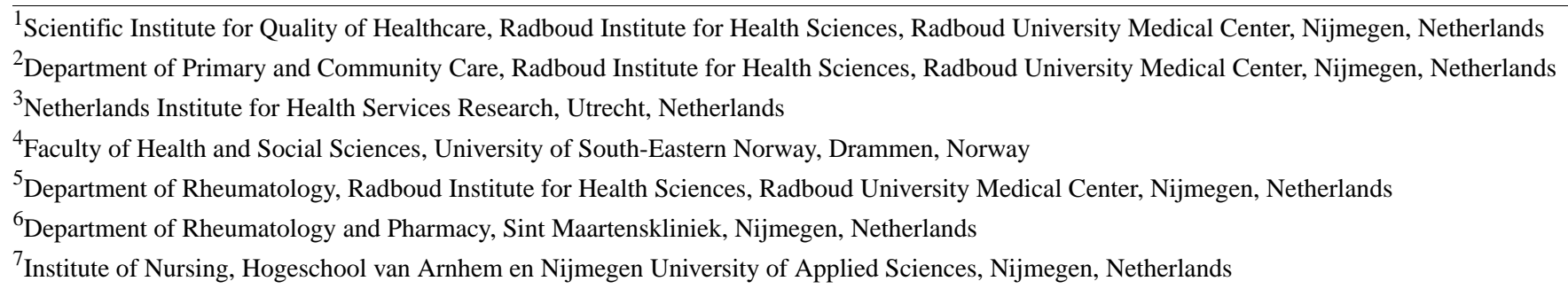

\section{Corresponding Author:}

Rixt Zuidema, MSc

Scientific Institute for Quality of Healthcare

Radboud Institute for Health Sciences

Radboud University Medical Center

Postbus 9101, Huispost 114

Nijmegen, PO Box 9101, 6500

Netherlands

Phone: 3124365567

Email: rixt.zuidema@ radboudumc.nl

\section{Abstract}

Background: Web-based self-management enhancing programs have the potential to support patients with rheumatoid arthritis (RA) in their self-management; for example, improve their health status by increasing their self-efficacy or taking their prescribed medication. We developed a Web-based self-management enhancing program in collaboration with RA patients and professionals as co-designers on the basis of the intervention mapping framework. Although self-management programs are complex interventions, it is informative to perform an explorative randomized controlled trial (RCT) before embarking on a larger trial.

Objective: This study aimed to evaluate the efficacy of a Web-based self-management enhancing program for patients with RA and identify outcome measures most likely to capture potential benefits.

Methods: A multicenter exploratory RCT was performed with an intervention group and a control group. Both groups received care as usual. In addition, the intervention group received 12 months of access to a Web-based self-management program. Assessment occurred at baseline, 6 months, and 12 months. Outcome measures included self-management behavior (Patient Activation Measurement, Self-Management Ability Scale), self-efficacy (Rheumatoid Arthritis task-specific Self-Efficacy, Perceived Efficacy in Patient-Physician Interaction), general health status (RAND-36), focus on fatigue (Modified Pain Coping Inventory for Fatigue), and perceived pain and fatigue (Numeric Rating Scales). A linear mixed model for repeated measures, using the intention-to-treat principle, was applied to study differences between the patients in the intervention ( $\mathrm{n}=78)$ and control $(n=79)$ groups. A sensitivity analysis was performed in the intervention group to study the influence of patients with high $(\mathrm{N}=30)$ and low $(\mathrm{N}=40)$ use of the intervention.

Results: No positive effects were found regarding the outcome measurements. Effect sizes were low.

Conclusions: Based on these results, it is not possible to conclude on the positive effects of the intervention or to select outcome measures to be regarded as the primary/main or secondary outcomes for a future trial. A process evaluation should be performed to provide more insight into the low compliance with and effectiveness of the intervention. This can determine for whom this sort of program will work and help to fine-tune the inclusion criteria.

Trial Registration: Netherlands Trial Register NTR4871; https://www.trialregister.nl/trial/4726 
(J Med Internet Res 2019;21(4):e12463) doi: 10.2196/12463

\section{KEYWORDS}

self-management; internet; arthritis, rheumatoid

\section{Introduction}

\section{Background}

Rheumatoid arthritis (RA) is one of the most prevalent chronic conditions, with a pervasive impact on daily life [1]. Despite the introduction of biological therapies and conventional disease-modifying antirheumatic drugs, RA patients experience a high level of pain [2] and fatigue [3,4], which leads to disabilities like restrictions in work participation [5,6] and leisure activities [7-9]. Moreover, many RA patients experience disease-related psychological problems, like depressive mood and helplessness [10,11].

To optimally manage the consequences of RA and reduce the impact of the disease on patients in daily life, effective self-management programs are needed. Web-based self-management programs can easily reach a large group of RA patients in their own place and time and provide more anonymity than face-to-face programs. Studies have shown that patients feel more comfortable sharing sensitive information like reports on daily activity or feelings online [12]. Other advantages are the possibility of tailoring information, avoiding waiting lists, and 24-hour availability [13].

Studies about Web-based self-management programs have shown to be effective in RA patients on several health outcomes, including increased self-efficacy, knowledge and physical activity [14], less pain, disability and depression, and reduction in the overuse of medication and the number of visits to physicians [15-17]. However, many of the programs are developed without end-user involvement. Consequently, these programs may not suit patient support needs for self-management as patient preferences for program use are not well known [18,19].

To guarantee optimal patient involvement, we developed a Web-based self-management program on the basis of intervention mapping (IM), called Reuma zelf te lijf (Coping with RA) [20-22]. According to the Medical Research Council (MRC), complex interventions such as this program can be evaluated in a randomized controlled trial (RCT); however, it is advised to first perform an explorative study investigating potential outcome measurements to be used in a larger trial [23].

\section{Objectives}

Therefore, the present explorative RCT study in patients with RA was aimed as follows: (1) to explore the potential efficacy of a Web-based self-management enhancing program versus "usual care" on self-management behavior, self-efficacy, general health status, coping with fatigue and the level of pain and fatigue and to determine the effect sizes at 6 and 12 months after baseline, and (2) to identify outcome measures most likely to capture the potential benefits covered by the performance objectives, by exploring their floor and ceiling effects at baseline.

\section{Methods}

\section{Design}

A multicenter exploratory RCT was conducted in 2 Dutch hospitals, The Radboudumc (a University hospital) and the Sint Maartenskliniek (a specialized hospital in rheumatology, rehabilitation, and orthopedic surgery), both located in Nijmegen, the Netherlands. An intervention and a control group were compared at 6 and 12 months after baseline on 6 outcome measurements to explore the efficacy of the Web-based program and to identify outcome measures [20]. The trial is registered at the Netherlands Trial Register (ID: NTR4871).

\section{Ethical Approval}

The medical ethics committee of Arnhem-Nijmegen approved this study (No. 2014-1208).

\section{Participants}

Between December 2014 and June 2015, patients with a diagnosis of RA aged 18 years or older were invited by a letter to participate in this study, in collaboration with rheumatologists, until the required number of 190 patients was reached. Patients received the following: (1) information about the study, (2) a questionnaire for screening eligibility, and (3) an informed consent form. Eligibility criteria were the ability to speak and read Dutch and having access to a computer with an internet connection. Patients receiving psychiatric or psychological treatment were excluded. Patients willing to participate were asked to return the informed consent with the completed questionnaire. When patients agreed to participate and were eligible, the researcher sent the patient an email with the baseline questionnaire.

\section{Randomization}

Eligible patients were stratified by the hospital and randomly assigned to the intervention or control group by an independent statistician using an automated randomization program. The researcher informed the patients by post if they were allocated to the control or intervention group. Patients in the control group continued with their care as usual, which comprised medical treatment at the outpatient clinic. The patients in the intervention group received, in additional to their care as usual, 12 months of access to the intervention directly after randomization. 
Table 1. Overview of the 9 modules and their performance objectives.

\begin{tabular}{ll}
\hline Module name & Performance objective: Patients need to... \\
\hline Balancing activity and rest & $\begin{array}{l}\text {...find balance between rest and activity; make choices when participating in daily life activities to keep } \\
\text { balance }\end{array}$ \\
$\begin{array}{l}\text { Setting boundaries } \\
\text { Asking for help and social support }\end{array}$ & $\begin{array}{l}\text {...ask for social support or practical help from their partner, relatives, colleagues and social environment } \\
\text { in daily life; ask for social support and practical help from colleagues; accept receiving social support } \\
\text { or practical help from their partner, relatives, colleagues and social environment in daily life }\end{array}$ \\
Use of medicines & $\begin{array}{l}\text {...take prescribed medication } \\
\text { Communication with health professionals }\end{array}$ \\
$\begin{array}{l}\text {...prepare for a visit to a health professional; ask questions and/or express concerns during an appointment } \\
\text { with a health professional }\end{array}$ \\
$\begin{array}{l}\text { Performing physical exercises } \\
\text { Coping with worries }\end{array}$ \\
$\begin{array}{l}\text { C...perform daily physical exercises } \\
\text { Coping with RA }\end{array}$ \\
\hline
\end{tabular}

${ }^{\mathrm{a}} \mathrm{RA}$ : rheumatoid arthritis.

\section{Intervention}

\section{Web-Based Self-Management Enhancing Program}

The intervention was developed between January 2013 and July 2014 in collaboration with RA patients and professionals as co-designers [20,24]. The theory of planned behavior was used as the underlying theory and essential behavioral change techniques were applied to induce behavioral change formulated as performance objectives, selected according to the IM steps $[21,25,26]$. The Web-based self-management enhancing program comprises 9 modules with 13 performance objectives (Table 1) and a diary to track patients' fatigue and pain over time [20]. Each module comprises 2-5 sessions, with informational and persuasive texts, videos with instructions and role models, exercises, and assignments. The program is unguided, and patients need to choose a module by their own and can work through it at their own pace whenever they want.

\section{Implementation of the Web-Based Self-Management Enhancing Program}

To implement the Web-based program and to increase use of the program by patients, 3 implementation strategies were deployed during the study: (1) patients received a written instruction manual for the program, (2) reminders to (re)visit the program were sent twice weekly via email, and (3) nurses brought the program to the attention of the intervention group participants during their consultation.

\section{Measurements and Outcomes}

All included patients who filled in the baseline questionnaire between January 2015 and June 2015 received a questionnaire after 6 months (T1) and 12 months (T2). At baseline, demographic and disease characteristics were assessed. Patient-reported outcome measurements were assessed at baseline and during follow-ups (T1 and T2). When patients preferred a paper questionnaire, a version was sent by post. When patients did not return the questionnaire at $\mathrm{T} 1$ but filled in the questionnaire at $\mathrm{T} 2$, this was indicated as a missing value at T1. Patients who did not return the $\mathrm{T} 2$ questionnaire are indicated as dropouts.

\section{Baseline Characteristics}

The following demographic and disease characteristics were assessed: age, gender, education level, employment status, disease duration, Numeric Rating Scales (NRS) pain/fatigue, Modified Health Assessment Questionnaire (M-HAQ) physical disability, and satisfaction with health status. The M-HAQ comprises 8 questions on difficulties in daily activities in the following domains: dressing, rising, eating, walking, hygiene, reaching, gripping, and usual activities. Patients responded on a 4-point scale, with a higher score indicating more difficulty in performing daily activities. Health satisfaction was assessed using 1 question about patients' (dis)satisfaction about the course of their disease last week, with 4 response options, with a higher score meaning less satisfied than before and an "I don't know" option [27].

\section{Outcome Measurements}

Based on the theory of planned behavior, 6 outcome measures were relevant: self-management behavior, self-efficacy, general health status, coping with fatigue, and the level of pain and fatigue.

\section{Self-Management Behavior}

The Patient Activation Measurement (PAM-13) includes statements about individuals' knowledge, confidence, and skills for self-management of their chronic illness behavior and the level of activation. It includes 13 items on a 5-point scale with a higher score indicating a higher level of patient activation. The scores of the 13 items are summarized as a total score. Total PAM scores were computed if at least 10 items were completed [28].

The short Self-Management Ability Scale (SMAS-S) comprises 18 items scored on a 6-point scale with a higher score indicating better self-management behavior [29]. 


\section{Self-Efficacy}

The Rheumatoid Arthritis task-specific Self-Efficacy (RASE) questionnaire comprises 28 items scored on a 5-point Likert scale. Higher scores reflect higher self-efficacy [30]. This questionnaire was translated into Dutch via forward-backward translation and decisions were based on consensus with a group of 5 researchers, 4 RA patients, and 1 RA patient who was a native English speaker. The Perceived Efficacy in Patient-Physician Interaction (PEPPI-5) comprises a 5-point Likert scale. A higher score reflects more confidence in patient interactions with their physician [31].

\section{General Health Status}

The RAND-36 comprises 36 questions measuring 8 dimensions: physical functioning, social functioning, physical role limitations, emotional role limitations, mental health, vitality, pain, perceived health-related quality of life and behavioral change, with various response options based on 3- to 6-point Likert scales, with a higher score indicating better perceived health-related quality of life. Scores were transformed to a 0-100-point scale for each subscale [32].

\section{Level of Pain and Fatigue}

Pain and fatigue were measured with NRS, ranging from 0 to 10 with 0 indicating no pain/fatigue and 10 indicating severe pain/very tired. For both outcomes, 2 questions were asked: the level of pain/fatigue today and the mean level of pain/fatigue during the last 2 weeks.

\section{Coping with Fatigue}

The Modified Pain Coping Inventory for Fatigue (MPCI-F) was used. This questionnaire is based on a subscale of the Pain Coping Inventory questionnaire and modified to assess coping with fatigue instead of coping with pain [33]. The questionnaire comprises 8 items to assess the focus on fatigue. A higher score reflects more focus on fatigue.

\section{Statistical Analysis}

Descriptive statistics were used to describe the control and intervention groups at baseline. $t$ tests and Chi-square tests were used to analyze baseline differences. It was analyzed whether the patients who dropped out differed from the group that returned the questionnaire at T2 [34]. Between-group differences in outcomes were analyzed using a linear mixed model to account for repeated measurements and to handle missing data under the missing-at-random assumption. Differences between the intervention and control groups were analyzed at baseline, after 6 months (T1), and 12 months (T2). The fixed variables in the model were as follows: group (intervention/control), hospital (hospital 1 or hospital 2), age, gender, disease duration, education level, employment status, physical functioning (M-HAQ), and the interaction terms between measurement time points and groups. The first analysis was done using the intention-to-treat principle. Subsequently, a sensitivity analysis was performed to explore the influence of program use within the intervention group. The intervention group was divided into 3 groups: (1) a group with low usage (0-1 visits), (2) a group with moderate usage (2-5 visits), and (3) a group with high usage ( 6 or more visits). In the analysis, the group with moderate usage was left out to increase the contrast between the groups with low and high usage. $t$ tests and Chi-square tests were performed to analyze between-group differences in demographics, disease-related characteristics, and outcomes at baseline, T1, and T2. Statistical significance was defined as $P<.05$.

For all outcome measurements, Cohen $d$ was used to quantify effect sizes by calculating the difference in means, divided by the pooled within-group standard deviation [35]. Following Cohen definition of effect sizes, less than 0.4 was defined as a small effect, between 0.5 and 0.7 as moderate, and $\geq 0.8$ was considered as a large effect [36]. Floor and ceiling effects were explored for all outcome measures by examining the percentage of minimum and maximum scores, which reflects the extent that patients scored the lowest or the highest score. For a 3- or 5-point Likert scale, floor and ceiling effects were defined as more than $80 \%$ of the patients scoring the lowest/highest. Statistical analyses were performed using SPSS version 22 (SPSS Inc) for Windows. For exploratory RCT such as these, sample sizes are not calculated based on formal power analyses. For this trial, a sample size of 200 patients was chosen, which was considered a sufficient size for a representation of the relevant variation in the target group.

\section{Results}

\section{Overview}

In total, 669 patients were eligible and invited. Of these, 191 patients expressed interest and 189 met the inclusion criteria (see Figure 1). In total, 157 patients completed the baseline questionnaire between January 2015 and June 2015. These patients were randomly assigned to the intervention group $(n=78)$ and the control group $(n=79)$, stratified by hospital. At T1, 59 in the intervention group and 65 in the control group filled in the questionnaire. At T2, 54 patients in the intervention group and 74 patients in the control group completed the questionnaire. Overall, in the intervention group, few patients $(69 \%, 54 / 78)$ participated at $\mathrm{T} 2$ than in the control group $(94 \%$, 74/79). Most of these patients gave the burden of their illness as the reason for dropout. Some patients refused to fill in the questionnaire at $\mathrm{T} 1$ but completed the questionnaire at $\mathrm{T} 2$, which explains the higher number of patients who filled in the questionnaire at $\mathrm{T} 2$ compared with $\mathrm{T} 1$. Differences in demographics and disease-related characteristics between the group of patients who refused to fill in the questionnaire at $\mathrm{T} 2$ and the group who returned the questionnaire at $\mathrm{T} 2$ were small $(<10 \%)$, which indicated that dropout did not influence the outcomes. 
Figure 1. CONSORT flow diagram.

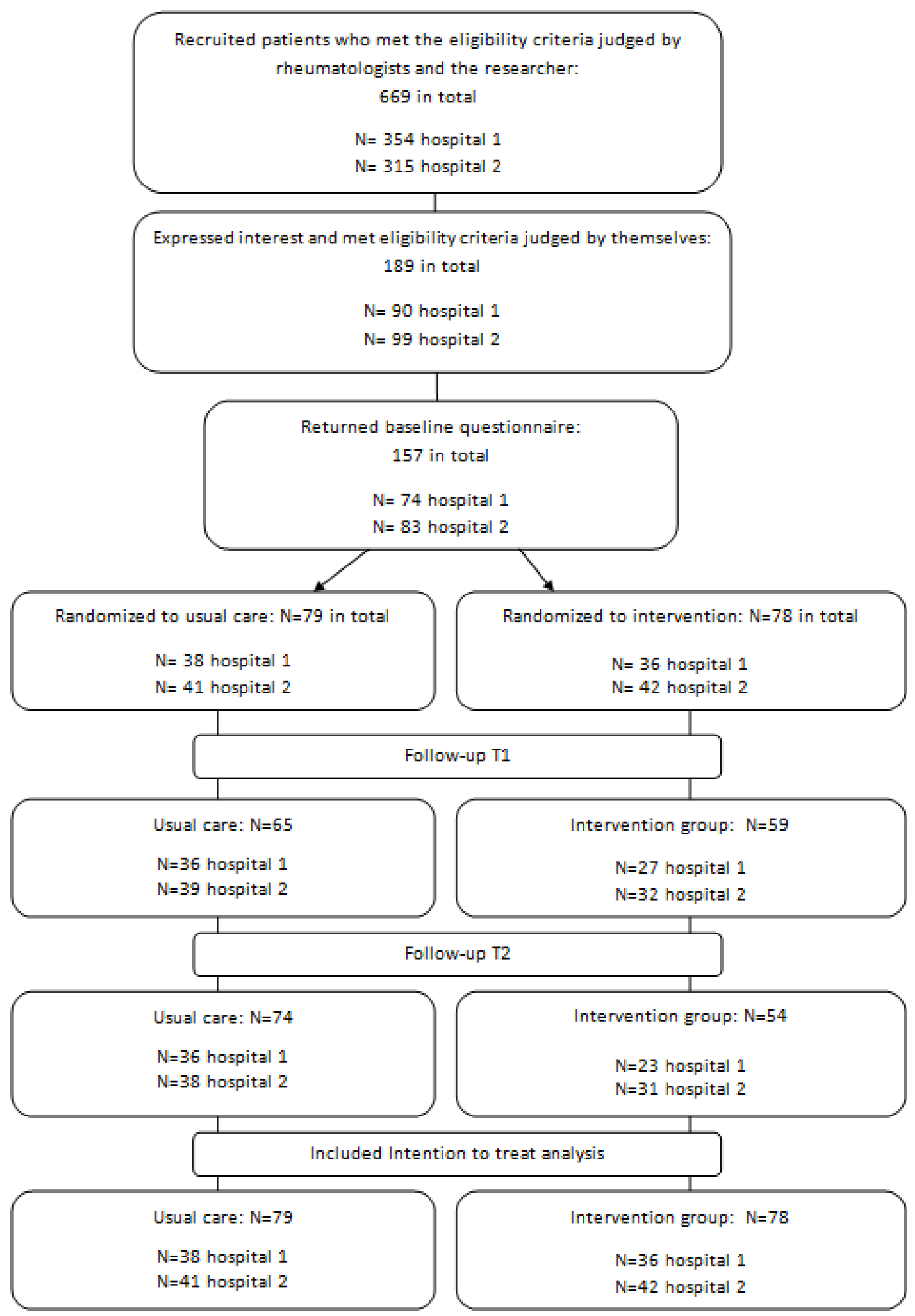


Table 2. Demographics and disease-related characteristics at baseline.

\begin{tabular}{|c|c|c|c|c|}
\hline \multirow[t]{2}{*}{ Characteristics } & \multicolumn{2}{|c|}{ Control group } & \multicolumn{2}{|c|}{ Intervention group } \\
\hline & $\mathrm{N}$ & Statistics & $\mathrm{N}$ & Statistics \\
\hline Age (years), mean (SD) & & $62.9(10.2)$ & & $61.0(11.3)$ \\
\hline \multicolumn{5}{|l|}{ Gender, \% } \\
\hline Men & 27 & 34 & 27 & 35 \\
\hline Women & 52 & 66 & 51 & 65 \\
\hline Disease duration, median (25th, 75 th percentiles) & 79 & $17(6.0,26)$ & 77 & $9(5.0,19.5)$ \\
\hline \multicolumn{5}{|l|}{ Education level, \% } \\
\hline Low & 28 & 35 & 10 & 13 \\
\hline Medium & 28 & 35 & 43 & 55 \\
\hline High & 23 & 29 & 25 & 32 \\
\hline \multicolumn{5}{|l|}{ Employment status, \% } \\
\hline Not working & 50 & 63 & 41 & 53 \\
\hline Part-time working & 7 & 9 & 7 & 9 \\
\hline Working & 22 & 28 & 30 & 39 \\
\hline Physical disability (M-HAQ $\left.{ }^{\mathrm{a}}\right)$, median (25th, 75th percentiles) & 79 & $0.5(0.1,1.4)$ & 78 & $0.6(0.1,1.1)$ \\
\hline NRS pain today, mean (SD) & 79 & $3.3(2.3)$ & 77 & $3.2(2.2)$ \\
\hline NRS mean pain last 2 weeks, mean (SD) & 79 & $3.9(2.3)$ & 78 & $3.6(2.3)$ \\
\hline NRS fatigue today (NRS), mean (SD) & 79 & $4.1(2.5)$ & 78 & $3.8(2.4)$ \\
\hline NRS mean fatigue last 2 weeks, mean (SD) & 79 & $4.3(2.4)$ & 78 & $4.3(2.3)$ \\
\hline
\end{tabular}

${ }^{\mathrm{a}}$ M-HAQ: Modified Health Assessment Questionnaire.

\section{Baseline Characteristics of Patients}

Demographics and disease-related characteristics at baseline were compared for the control group and the intervention group, as shown in Table 2. The only significant between-group difference in the patient characteristics was education level $(P=.003)$. Fewer patients in the intervention group had a lower education level (12.8\% vs 35.4\%) and more patients had a moderate $(55.1 \%$ vs $35.4 \%)$ or higher education level $(32.1 \%$ vs $29.1 \%$ ). Some patients who filled in a paper questionnaire did not complete all items, which explains the missing data in Tables 3 and 4 .

\section{The Outcome Measurements at Baseline and Follow-up}

Table 3 gives an overview of the mean scores of outcome measurements of the patients in the intervention and control groups at baseline and after 6 and 12 months. The baseline scores of the 2 groups did not differ significantly. 
Table 3. Mean scores of outcome measurements on baseline, $\mathrm{T} 1$ and $\mathrm{T} 2$ of control and intervention groups.

\begin{tabular}{|c|c|c|c|c|c|c|}
\hline \multirow[t]{2}{*}{ Scales, group } & \multicolumn{2}{|c|}{ Baseline (T0) } & \multicolumn{2}{|l|}{$\mathrm{T} 1$} & \multicolumn{2}{|l|}{$\mathrm{T} 2$} \\
\hline & $\mathrm{N}$ & Mean (SD) & $\mathrm{N}$ & Mean (SD) & $\mathrm{N}$ & Mean (SD) \\
\hline \multicolumn{7}{|l|}{ PAM $^{a}(10-65)$} \\
\hline Control & 57 & $46.9(4.9)$ & 49 & $47.7(4.8)$ & 45 & $47.8(3.8)$ \\
\hline Intervention & 47 & $47.2(3.7)$ & 35 & 46.7 (6.9) & 31 & $47.8(2.9)$ \\
\hline \multicolumn{7}{|l|}{ SMAS-S $^{\mathbf{b}}(0-60)$} \\
\hline Control & 79 & $36.0(6.3)$ & 75 & $37.9(6.8)$ & 74 & $37.6(6.8)$ \\
\hline Intervention & 78 & $36.7(7.1)$ & 57 & $39.4(6.4)$ & 54 & $38.8(7.0)$ \\
\hline \multicolumn{7}{|l|}{$\operatorname{RASE}^{c}(28-140)$} \\
\hline Control & 79 & $99.4(12.7)$ & 75 & $101.5(10.6)$ & 74 & 99.9 (11.6) \\
\hline Intervention & 78 & $102.9(10.2)$ & 57 & $101.9(10.3)$ & 54 & $102.0(7.4)$ \\
\hline \multicolumn{7}{|l|}{ PEPPI-5 $^{d}(5-25)$} \\
\hline Control & 79 & $21.6(3.0)$ & 75 & $21.0(3.2)$ & 73 & $20.6(3.4)$ \\
\hline Intervention & 78 & $21.2(3.3)$ & 57 & $21.3(3.1)$ & 54 & $20.8(3.1)$ \\
\hline \multicolumn{7}{|c|}{ RAND physical functioning (0-100) } \\
\hline Control & 78 & $58.1(27.0)$ & 75 & $59.4(26.5)$ & 74 & $61.8(25.9)$ \\
\hline Intervention & 77 & $61.7(26.1)$ & 57 & $65.9(27.3)$ & 54 & $65.9(26.7)$ \\
\hline \multicolumn{7}{|c|}{ RAND social functioning (0-100) } \\
\hline Control & 79 & $73.3(2476)$ & 75 & $72.7(22.3)$ & 74 & $73.1(22.4)$ \\
\hline Intervention & 78 & $71.3(20.8)$ & 57 & $77.0(19.6)$ & 54 & $70.8(24.3)$ \\
\hline \multicolumn{7}{|c|}{ RAND physical role limitations $(0-100)$} \\
\hline Control & 79 & $49.1(43.6)$ & 75 & $51.11(45.3)$ & 74 & $49.0(43.1)$ \\
\hline Intervention & 78 & $49.0(43.3)$ & 56 & $57.9(42.0)$ & 54 & $49.1(44.2)$ \\
\hline \multicolumn{7}{|c|}{ RAND emotional role limitations (0-100) } \\
\hline Control & 79 & $75.1(40.5)$ & 73 & $84.9(35.2)$ & 74 & $78.8(39.2)$ \\
\hline Intervention & 77 & $80.1(36.4)$ & 54 & $85.2(31.5)$ & 54 & $78.4(37.3)$ \\
\hline \multicolumn{7}{|c|}{ RAND mental health (0-100) } \\
\hline Control & 78 & $54.7(14.3)$ & 75 & $72.6(16.7)$ & 74 & $76.1(14.6)$ \\
\hline Intervention & 78 & $52.6(13.4)$ & 56 & $76.5(12.0)$ & 54 & $75.9(13.8)$ \\
\hline \multicolumn{7}{|c|}{ RAND vitality (0-100) } \\
\hline Control & 78 & $51.2(22.7)$ & 75 & $53.9(21.6)$ & 74 & $56.3(21.2)$ \\
\hline Intervention & 78 & $53.1(19.4)$ & 56 & $61.2(15.1)$ & 54 & $62.5(14.5)$ \\
\hline \multicolumn{7}{|c|}{ RAND pain $(0-100)$} \\
\hline Control & 79 & $59.9(21.3)$ & 75 & $60.8(22.2)$ & 74 & $66.1(21.8)$ \\
\hline Intervention & 78 & $64.3(22.3)$ & 57 & $67.1(21.0)$ & 54 & $63.9(22.1)$ \\
\hline \multicolumn{7}{|c|}{ RAND general health perception $(0-100)$} \\
\hline Control & 79 & $52.5(18.7)$ & 75 & $47.8(18.3)$ & 72 & $48.1(17.5)$ \\
\hline Intervention & 77 & $52.7(20.8)$ & 57 & $52.3(19.5)$ & 48 & $50.4(19.1)$ \\
\hline \multicolumn{7}{|c|}{ RAND health change (0-100) } \\
\hline Control & 79 & $44.9(21.2)$ & 75 & $50.3(19.9)$ & 74 & $44.3(19.7)$ \\
\hline Intervention & 78 & $47.8(23.2)$ & 57 & $51.3(20.8)$ & 54 & $43.5(23.9)$ \\
\hline$N_{R S}^{e}$ pain today & & & & & & \\
\hline
\end{tabular}




\begin{tabular}{|c|c|c|c|c|c|c|}
\hline \multirow[t]{2}{*}{ Scales, group } & \multicolumn{2}{|c|}{ Baseline (T0) } & \multicolumn{2}{|l|}{$\mathrm{T} 1$} & \multicolumn{2}{|l|}{$\mathrm{T} 2$} \\
\hline & $\mathrm{N}$ & Mean (SD) & $\mathrm{N}$ & Mean (SD) & $\mathrm{N}$ & Mean (SD) \\
\hline Control & 79 & $3.3(2.3)$ & 75 & $3.2(2.2)$ & 72 & $3.0(2.2)$ \\
\hline Intervention & 77 & $3.2(2.2)$ & 57 & $3.0(2.3)$ & 48 & $3.3(2.3)$ \\
\hline \multicolumn{7}{|c|}{ NRS mean pain last 2 weeks $(0-10)$} \\
\hline Control & 79 & $3.9(2.3)$ & 75 & $3.8(2.1)$ & 72 & $3.6(2.2)$ \\
\hline Intervention & 78 & $3.6(2.3)$ & 57 & $3.4(2.3)$ & 48 & $3.9(2.4)$ \\
\hline \multicolumn{7}{|c|}{ NRS fatigue today $(0-10)$} \\
\hline Control & 79 & $4.1(2.5)$ & 75 & $3.8(2.6)$ & 72 & $3.7(2.3)$ \\
\hline Intervention & 78 & $3.8(2.4)$ & 57 & $3.4(2.4)$ & 48 & $3.6(2.4)$ \\
\hline \multicolumn{7}{|c|}{ NRS mean fatigue last 2 weeks $(0-10)$} \\
\hline Control & 79 & $4.3(2.4)$ & 75 & $4.2(2.6)$ & 72 & $4.2(2.4)$ \\
\hline Intervention & 78 & $4.3(2.3)$ & 57 & $3.7(2.1)$ & 48 & $4.0(2.2)$ \\
\hline \multicolumn{7}{|l|}{$\operatorname{MPCI}^{\mathbf{f}}{ }^{(4-32)}$} \\
\hline Control & 79 & $14.1(4.8)$ & 75 & $14.1(4.7)$ & 74 & $13.6(4.3)$ \\
\hline Intervention & 78 & $14.1(3.9)$ & 57 & $13.3(3.3)$ & 54 & $13.6(3.2)$ \\
\hline
\end{tabular}

a PAM: Patient Activation Measurement.

${ }^{\mathrm{b}}$ SMAS-S: short Self-Management Ability Scale.

${ }^{c}$ RASE: Rheumatoid Arthritis Self-Efficacy.

${ }^{\mathrm{d}}$ PEPPI-5: Perceived Efficacy in Patient-Physician Interaction.

${ }^{\mathrm{e}} \mathrm{NRS}$ : numerical rating scale.

${ }^{f}$ MPCI-F: Modified Pain Coping Inventory for Fatigue.

In Table 4, the estimated differences between the intervention and control groups of the intention-to-treat analysis at 6 and 12 months are presented. Overall, the scores show no significant differences and small effect sizes. Only the outcome measurement of the subscale RAND-36 vitality at T2 (5.4195\% CI $0.16-10.65, P=.04)$ showed a significant difference with respect to T0, with a small effect size (Cohen $d$ ) of 0.01 in favor of the intervention group. Floor and ceiling effects were explored for all specified outcomes at baseline but were not found.

\section{Sensitivity Analysis}

\section{Baseline Characteristics of Patients}

High users of the intervention scored statistically significantly better than low users of the intervention on the following

baseline characteristics: physical disability (M-HAQ; $P=.03$ ), RAND-36 subscale social functioning $(P=.02)$, RAND-36 subscale physical role limitations $(P=.03)$, RAND-36 pain $(P=.03)$, and all the NRS scales, that is, pain today $(P=.002)$, mean pain last 2 weeks $(P=.02)$, fatigue today $(P<.001)$ and mean fatigue last 2 weeks $(P<.001$; see Table 5).

After performing the sensitivity analysis, a statistically significant effect was found for the group with high usage on the subscale RAND-36 general health perception after 12 months $(9.65,95 \%$ CI $0.83-18.48, P=.03)$, with a small effect size of 0.02 (Table 6). No floor and ceiling effects were found for any of the specified outcomes at baseline in the groups with low or high usage. 
Table 4. The estimated group differences between intervention and control groups after intention-to-treat analysis at 6 months and 12 months after baseline.

\begin{tabular}{|c|c|c|c|c|c|c|c|c|}
\hline \multirow[t]{2}{*}{ Scales } & \multicolumn{4}{|c|}{6 months after baseline } & \multicolumn{4}{|c|}{12 months after baseline } \\
\hline & $\begin{array}{l}\text { T0-T1 } \\
\text { change }\end{array}$ & $95 \% \mathrm{CI}$ & $P$ value $^{\mathrm{a}}$ & Cohen $d$ & $\begin{array}{l}\text { T0-T2 } \\
\text { change }\end{array}$ & $95 \% \mathrm{CI}$ & $P$ value $^{\mathrm{a}}$ & Cohen $d$ \\
\hline PAM $^{\mathrm{b}}(10-65)$ & -0.7 & -3.4 to 1.5 & .44 & 0.0 & -0.1 & -1.6 to 1.5 & .93 & 0.00 \\
\hline SMAS-S $^{\mathrm{c}}(0-60)$ & 0.3 & -1.4 to 2.0 & .72 & 0.0 & 0.7 & -1.1 to 2.5 & .43 & 0.03 \\
\hline $\operatorname{RASE}^{\mathrm{d}}(28-140)$ & -2.1 & -4.9 to 0.8 & .16 & 0.0 & 0.3 & -2.2 to 2.9 & .81 & 0.00 \\
\hline PEPPI-5 $5^{\mathrm{e}}(5-25)$ & 0.4 & -0.5 to 1.2 & .40 & 0.0 & 0.3 & -0.7 to 1.3 & .51 & 0.03 \\
\hline RAND $^{f}$ physical functioning $(0-100)$ & 2.5 & -3.3 to 8.1 & .40 & 0.00 & -0.2 & -5.4 to 5.1 & .96 & 0.00 \\
\hline RAND social functioning (0-100) & 4.1 & -1.5 to 9.6 & .15 & 0.0 & -2.7 & -9.2 to 3.8 & .42 & -0.01 \\
\hline RAND physical role limitations $(0-100)$ & 5.6 & -7.0 to 18.2 & .38 & 0.00 & -2.8 & -14.9 to 9.3 & .65 & 0.00 \\
\hline RAND emotional role limitations $(0-100)$ & -3.2 & -14.1 to 7.6 & .56 & 0.00 & -3.9 & -16.0 to 8.3 & .53 & 0.00 \\
\hline RAND mental health $(0-100)$ & 2.8 & -1.1 to 6.8 & .16 & 0.0 & 0.9 & -3.0 to 4.7 & .66 & 0.00 \\
\hline RAND vitality $(0-100)$ & 3.4 & -1.5 to 8.3 & .17 & 0.0 & 5.4 & 0.2 to 10.7 & $.04^{\mathrm{g}}$ & 0.01 \\
\hline RAND pain $(0-100)$ & 2.6 & -3.7 to 8.9 & .42 & 0.0 & -6.1 & -12.5 to 0.4 & .06 & -0.01 \\
\hline RAND general health perception (0-100) & 2.2 & -2.2 to 6.7 & .33 & 0.0 & -0.1 & -4.5 to 4.4 & .98 & 0.00 \\
\hline RAND health change $(0-100)$ & 0.1 & -6.8 to 7.1 & .97 & 0.00 & -1.4 & -9.0 to 6.2 & .72 & 0.00 \\
\hline $\mathrm{NRS}^{\mathrm{h}}$ pain today $(0-10)$ & 0.0 & -0.6 to 0.7 & .97 & 0.00 & 0.5 & -0.1 to 1.2 & .13 & 0.10 \\
\hline NRS mean pain last 2 weeks $(0-10)$ & 0.0 & -0.7 to 0.6 & .97 & 0.00 & 0.7 & 0.0 to 1.4 & .60 & 1.13 \\
\hline NRS fatigue today $(0-10)$ & 0.2 & -0.5 to 0.8 & .66 & 0.0 & 0.3 & -0.4 to 0.9 & .46 & 0.01 \\
\hline NRS mean fatigue last 2 weeks $(0-10)$ & -0.23 & -0.9 to 0.4 & .45 & -0.1 & 0.1 & -0.6 to 0.7 & .81 & 0.00 \\
\hline MPCI-F $F^{\mathrm{i}}(4-32)$ & 0.1 & -0.8 to 0.9 & .90 & 0.00 & 0.3 & -0.7 to 1.2 & .58 & 0.01 \\
\hline
\end{tabular}

${ }^{\mathrm{a}}$ Values represent outcomes of the ITT analysis without confounders. After adding confounders, no changes in values appear.

bAM: Patient Activation Measurement.

${ }^{\mathrm{c}}$ SMAS-S: short Self-Management Ability Scale.

${ }^{\mathrm{d}}$ RASE: Rheumatoid Arthritis Self-Efficacy.

ePEPPI-5: Perceived Efficacy in Patient-Physician Interaction.

${ }^{f}$ RAND-36: General Health Status.

${ }^{\mathrm{g}}$ Significant differences $(P<.05)$ between control and intervention groups.

${ }^{\mathrm{h}}$ NRS: numerical rating scale.

${ }^{\mathrm{i}}$ MPCI-F: Modified Pain Coping Inventory for Fatigue. 
Table 5. Scores at baseline for the groups with a low and high usage of the intervention: demographic characteristics, disease-related characteristics, and outcome measures.

\begin{tabular}{|c|c|c|c|c|c|}
\hline \multirow[t]{2}{*}{ Characteristics and outcome measures at baseline } & \multicolumn{2}{|c|}{ Low usage } & \multicolumn{2}{|c|}{ High usage } & \multirow[t]{2}{*}{$P$ value } \\
\hline & $\mathrm{N}$ & Statistics & $\mathrm{N}$ & Statistics & \\
\hline Age (years), mean (SD) & 29 & $63.8(10.5)$ & 40 & $58.9(10.8)$ & .06 \\
\hline Gender, \% & & & & & .55 \\
\hline Men & 10 & 33 & 14 & 35 & \\
\hline Women & 20 & 67 & 26 & 65 & \\
\hline Disease duration, (median (25th, 75 th percentiles)) & 29 & $8,0(4,5,22,5)$ & 40 & $8,5(5,0,18,7)$ & .80 \\
\hline Education level, \% & & & & & .78 \\
\hline Low & 3 & 10 & 5 & 13 & \\
\hline Middle & 19 & 63 & 22 & 55 & \\
\hline High & 8 & 28 & 13 & 33 & \\
\hline Employment status, \% & & & & & .28 \\
\hline Not working & 22 & 73 & 23 & 58 & \\
\hline Working & 8 & 27 & 17 & 43 & \\
\hline $\begin{array}{l}\text { Physical disability (Modified Health Assessment Questionnaire), } \\
\text { (median [25th, 75th percentiles]) }\end{array}$ & 30 & $1.1(0.2,1.6)^{\mathrm{a}}$ & 40 & $0.5(0.1,1,0)$ & $.03^{\mathrm{a}}$ \\
\hline $\mathrm{PAM}^{\mathrm{b}}(10-65)$, mean $(\mathrm{SD})$ & 20 & $48.0(3.3)$ & 20 & $46.2(3.8)$ & .11 \\
\hline SMAS-S $^{\mathrm{c}}(0-60)$, mean (SD) & 30 & $36.5(7.3)$ & 40 & $37.7(7.0)$ & .48 \\
\hline $\operatorname{RASE}^{\mathrm{d}}(28-140)$, mean (SD) & 30 & $102.1(10.9)$ & 40 & $103.4(9.1)$ & .58 \\
\hline PEPPI- $5^{\mathrm{e}}(5-25)$, mean $(\mathrm{SD})$ & 30 & $21.5(3.9)$ & 40 & $21.2(2.8)$ & .68 \\
\hline RAND $^{f}$ physical functioning $(0-100)$, mean (SD) & 29 & $54.3(28.3)$ & 40 & $66.3(24.6)$ & .07 \\
\hline RAND social functioning (0-100), mean (SD) & 30 & $64.6(24.8)$ & 40 & $77.8(17.1)$ & $.02^{\mathrm{a}}$ \\
\hline RAND physical role limitations (0-100), mean (SD) & 30 & $36.7(43.9)$ & 40 & $60.0(42.7)$ & $.03^{\mathrm{a}}$ \\
\hline RAND emotional role limitations ( $0-100)$, mean (SD) & 29 & $74.7(41.5)$ & 40 & $85.8(33.7)$ & .24 \\
\hline RAND mental health (0-100), mean (SD) & 30 & $72.1(16.1)$ & 40 & $78.7(11.6)$ & .06 \\
\hline RAND vitality (0-100), mean (SD) & 30 & $53.1(22.9)$ & 40 & $61.7(15.4)$ & .08 \\
\hline RAND pain (0-100), mean (SD) & 30 & $56.9(25.5)$ & 40 & $69.8(19.2)$ & $.03^{\mathrm{a}}$ \\
\hline RAND general health perception (0-100), mean (SD) & 29 & $46.0(19.4)$ & 40 & $54.0(17.6)$ & .08 \\
\hline RAND health change (0-100), mean (SD) & 30 & $43.3(20.7)$ & 40 & $52.5(24.6)$ & .10 \\
\hline $\mathrm{NRS}^{\mathrm{g}}$ pain today $(0-10)$, mean $(\mathrm{SD})$ & 29 & $4.3(2.5)$ & 40 & $2.5(1.8)$ & $.002^{\mathrm{a}}$ \\
\hline NRS mean pain last 2 weeks $(0-10)$, mean (SD) & 30 & $4.4(2.5)$ & 40 & $3.1(2.1)$ & $.02^{\mathrm{a}}$ \\
\hline NRS fatigue today (0-10), mean (SD) & 30 & $4.8(2.4)$ & 40 & $3.0(2.2)$ & $<.001^{\mathrm{a}}$ \\
\hline NRS mean fatigue last 2 weeks $(0-10)$, mean (SD) & 30 & $4.8(2.4)$ & 40 & $3.0(2.2)$ & $<.001^{\mathrm{a}}$ \\
\hline MPCI-F $\mathrm{F}^{\mathrm{h}}$ (4-32), mean (SD) & 30 & $15.0(4.8)$ & 40 & $13.2(3.0)$ & .08 \\
\hline
\end{tabular}

${ }^{\mathrm{a}}$ Significant differences $(P<.05)$ between the group low and high users.

${ }^{b}$ PAM: Patient Activation Measurement.

${ }^{\mathrm{c}}$ SMAS-S: short Self-Management Ability Scale.

${ }^{\mathrm{d}}$ RASE: Rheumatoid Arthritis Self-Efficacy.

${ }^{\text {e}}$ PEPPI-5: Perceived Efficacy in Patient-Physician Interaction.

${ }_{\text {RAND-36: General Health Status. }}$

${ }^{\mathrm{g}}$ NRS pain/fatigue: Numeric Rating scales pain/fatigue. 
${ }^{\mathrm{h}}$ Coping with fatigue: Modified Pain Coping Inventory for Fatigue.

Table 6. The estimated difference between the group with low and high usage of the intervention after sensitivity analysis at 6 months and 12 months after baseline.

\begin{tabular}{|c|c|c|c|c|c|c|c|c|}
\hline \multirow[t]{2}{*}{ Scales } & \multicolumn{4}{|c|}{6 months after baseline } & \multicolumn{4}{|c|}{12 months after baseline } \\
\hline & $\begin{array}{l}\text { T0-T1 } \\
\text { change }\end{array}$ & $95 \% \mathrm{CI}$ & $P$ value $^{\mathrm{a}}$ & Cohen $d$ & $\begin{array}{l}\text { T0-T2 } \\
\text { change }\end{array}$ & $95 \% \mathrm{CI}$ & $P$ value $^{\mathrm{a}}$ & Cohen $d$ \\
\hline $\operatorname{PAM}^{\mathrm{b}}(10-65)$ & 2.4 & -1.7 to 6.4 & .24 & 0.12 & 0.0 & -2.9 to 2.9 & $>.99$ & 0.00 \\
\hline SMAS-S $^{\mathrm{c}}(0-60)$ & -0.4 & -3.4 to 2.7 & .82 & 0.00 & 1.3 & -2.0 to 4.5 & .44 & 0.02 \\
\hline $\operatorname{RASE}^{\mathrm{d}}(28-140)$ & -1.7 & -6.8 to 3.4 & .52 & -0.00 & -0.6 & -5.3 to 4.1 & .81 & 0.00 \\
\hline PEPPI- $5^{\mathrm{e}}(5-25)$ & -1.0 & -2.5 to 0.5 & .20 & -0.11 & -0.1 & -1.9 to 1.7 & .93 & 0.00 \\
\hline RAND $^{f}$ physical functioning $(0-100)$ & 9.2 & -0.7 to 19.2 & .07 & 0.01 & 2.2 & -7.4 to 11.8 & .65 & 0.00 \\
\hline RAND social functioning (0-100) & 1.5 & -8.4 to 11.4 & .76 & 0.00 & 5.3 & -6.7 to 17.4 & .38 & 0.01 \\
\hline RAND physical role limitations (0-100) & 7.4 & -14.7 to 29.5 & .51 & 0.00 & 3.7 & -18.6 to 25.9 & .74 & 0.00 \\
\hline RAND emotional role limitations $(0-100)$ & 16.1 & -3.6 to 35.7 & .11 & 0.01 & -1.7 & -24.5 to 21.0 & .88 & 0.00 \\
\hline RAND mental health $(0-100)$ & 0.8 & -6.3 to 7.9 & .83 & 0.00 & -4.2 & -11.2 to 2.8 & .24 & -0.02 \\
\hline RAND vitality $(0-100)$ & 2.9 & -5.6 to 11.5 & .50 & 0.01 & -1.2 & -10.8 to 8.4 & .81 & 0.00 \\
\hline RAND pain $(0-100)$ & 1.7 & -4.5 to 12.9 & .77 & 0.00 & 8.8 & -3.0 to 20.6 & .14 & 0.02 \\
\hline RAND general health perception $(0-100)$ & 2.9 & -5.1 to 10.8 & .48 & 0.01 & 9.7 & 0.8 to 18.5 & $.03^{\mathrm{g}}$ & 0.02 \\
\hline RAND health change $(0-100)$ & 8.3 & -4.0 to 20.5 & .19 & 0.02 & 6.4 & -7.9 to 20.6 & .38 & 0.01 \\
\hline $\mathrm{NRS}^{\mathrm{h}}$ pain today $(0-10)$ & 0.0 & -1.2 to 1.2 & $>.99$ & 0.00 & -0.6 & -1.9 to 0.8 & .41 & -0.11 \\
\hline NRS mean pain last 2 weeks $(0-10)$ & -0.6 & -1.8 to 0.5 & .29 & -0.12 & 0.9 & -2.3 to 0.6 & .24 & -0.16 \\
\hline NRS fatigue today $(0-10)$ & 0.2 & -1.0 to 1.3 & .73 & 0.03 & -0.9 & -2.2 to 0.5 & .22 & -0.14 \\
\hline NRS mean fatigue last 2 weeks $(0-10)$ & 0.2 & -1.0 to 1.3 & .78 & 0.03 & -0.5 & -1.7 to 0.8 & .51 & -0.08 \\
\hline MPCI-F ${ }^{\mathrm{i}}(4-32)$ & -0.2 & -1.7 to 1.3 & .76 & -0.01 & -0.4 & -2.1 to 1.3 & .67 & -0.01 \\
\hline
\end{tabular}

${ }^{\text {a}}$ Values represent outcomes of the ITT analysis without confounders. After adding confounders, no changes in values appear.

bAM: Patient Activation Measurement.

${ }^{\mathrm{c}}$ SMAS-S: short Self-Management Ability Scale.

${ }^{d}$ RASE: Rheumatoid Arthritis Self-Efficacy.

${ }^{\mathrm{e}}$ PEPPI-5: Perceived Efficacy in Patient-Physician Interaction.

${ }^{f}$ RAND-36: General Health Status.

${ }^{\mathrm{g}}$ Significant differences $(P<.05)$ between control and intervention groups.

${ }^{\mathrm{h}} \mathrm{NRS}$ : numerical rating scale.

${ }^{\mathrm{i}}$ MPCI-F: Modified Pain Coping Inventory for Fatigue.

\section{Discussion}

\section{Principal Findings}

This study aimed to evaluate the efficacy of a Web-based self-management enhancing program in patients with RA in an explorative trial on 6 outcomes: self-management behavior, self-efficacy, general health status, coping with fatigue, and the level of pain and fatigue. Results show no remarkable statistically significant difference between the intervention and control group. Moreover, effect sizes were low. Consequently, the results of this exploratory show no convincing trend regarding the efficacy of the program. This was unexpected as the theory-based intervention was carefully designed, according the IM steps, on the basis of patients support needs [37,38]. In addition, the range of outcome measures were selected carefully, and the study was well-performed. Randomization was successful, and the number of missing was limited. It was thought that the size was adequate for a pilot study $(\mathrm{N}=157)$.

Notably, the lack of a trend for a positive result is not in line with other studies, showing that self-management programs seem to be promising for patients with a chronic illness, including arthritis $[15,35]$. However, these studies cannot be compared with each other in a straightforward manner because of the various self-management approaches (eg, offering weekly vs nonweekly Web-based courses, with face-to-face help or without), various contents of the self-management programs, 
and the different outcome measures used in these studies [15,39]. For example, it is unexpected that our Web-based program yielded no results for RA patients, whereas the Web-based program evaluated by Lorig and colleagues [14] concluded that RA patients showed increased self-efficacy and improved health status for 4 of the 6 health status measures that were included [14]. These different results may be explained by the different questionnaires used for the same outcomes, that is, self-efficacy and health status.

Moreover, differences in the content and delivery of the programs could be a reason for the different results. Other programs focused on different topics (eg, pain/stress management, problem solving and nutrition, which were not covered by our program). In our program, patients received no help with logging into the program or using the program in contrast to the program described by Lorig et al [14], where patients received help and were encouraged to use the program. Patients could choose which modules to work through and follow it at their own speed. In the program described by Lorig et al [14], peer moderators helped patients log in and encouraged them to use the weekly program and moderate posts that patients could leave on the program website [14].

There are potentially 5 reasons for the lack of efficacy of our Web-based program: (1) the use of inappropriate outcome measures, (2) individual patients had no need for self-management support, (3) low usage of the program/high dropout of the intervention group, (4) inadequate embedding of the program in health care, and (5) not selecting the appropriate patients.

First, in the case of inappropriate outcome measures, it could be that the carefully selected validated questionnaires still did not exactly measure the pursued behavior changes formulated in the performance objectives. That is, the intervention aimed to result in specific self-management behaviors. The validated questionnaires comprised more generic questions and therefore did not exactly measure these specifically formulated behavioral changes in performance objectives (Table 1). However, it was expected that a positive significant result would be found on the RASE questionnaire, as this measures task-specific self-efficacy for patients with RA with items closely related to the specific formulated performance objectives. Finding no positive results suggests that it is possible that our intervention did not support patients in increasing their level of self-efficacy. This could mean that the absence of positive results is less driven by the choice of outcomes than by the other points discussed below.

Second, it could be that recruited patients did not have a perceived need for enhancing self-efficacy when they agreed to participate in the program. Although the program was developed on the basis of the support needs for self-management of RA patients, individual participating patients in this study were not asked whether, and if yes, what kind of support needs they had for self-management. It could be that patients differ in their needs and more tailoring toward individuals is needed, for example, preselection of the offered modules.

Third, the low usage of the program by patients in the intervention group could have resulted in finding only a significant effect on RAND-36 vitality, with a small effect size. The low usage of the program can have several reasons. As stated above, patients could have not felt a need for support. Another reason could be that patients were not motivated to change their behavior or had a negative attitude toward the Web-based program. The program comprised several elements to stimulate patients' usage of the program, such as persuasive texts or modeling videos. It could be that these elements did not work or that elements were lacking in the program. Moreover, the characteristics of the Web-based program, for example, attractiveness or the ease of logging in, are factors that could have influenced patient usage of the program. It was also notable that patients in the intervention group dropped out more than patients in the control group. A high dropout rate is a common finding in Web-based programs [40,41]. Crutzen et al (2015), gave as possible explanation for these higher dropout rates that patients in an intervention group have several expectations of the intervention. In cases where these expectations are not met or if patients feel the intervention is not supporting them, patients will refuse to fill in the measurements and will not revisit the program [42]. In this study, patients in the intervention group were significantly higher educated than in the control group. It could be that higher educated patients use more resources that could support them (eg, support of health professionals), which could lead to lower usage of the program.

Fourth, this program was not adequately embedded in patient care. Although nurses brought the program to the attention of intervention group patients during their consultation, they did not discuss the self-management topics of the program with patients to continue the support for self-management during consultations. It has been shown that self-management programs with the possibility of interacting with health professionals (blended care) can lead to positive results $[14,43]$.

Fifth, it could be that there was a selection bias in this study. Rheumatologists selected patients with diagnosis RA, aged 18 years, or were invited by letter to participate in this study, in collaboration with rheumatologists until the required number of 190 patients were reached. Probably, rheumatologists mainly selected the patients who had a low functional disability (health assessment questionnaire) as in their opinion, these patients would benefit of a self-management program the most.

\section{Recommendations}

Given the results of this study, relevant recommendations for future studies and practice can be given. First, using a questionnaire with questions referring to the program objectives is recommended to measure the effects in patient behavioral change [38]. For example, one of the performance objectives of this Web-based program, "set boundaries in their work situation," could be evaluated with an item like "I'm able to set boundaries with my colleagues in my work situation" (measuring skills). Patients can set their own objectives in the program, using goal setting as a strategy. Goal setting requires that patients set a clear, specific, and achievable goal to change their behavior. This concrete formulation of the goal ensures that the behavioral change is measurable [44]. 
Second, before inclusion, it is recommended to investigate whether patients have a need for self-management support and if so, what kind of support they need. A next step is to decide if patient support needs are handled in the program and to tailor the program to their support needs. This can avoid patients feeling that the program did not support them, which often results in no revisits. Investigation of support needs could take place over the telephone. This also offers the possibility of helping patients formulate their support needs, which is difficult to do in general.Third, to increase the usage of the program and limit dropout, during the development phase, it is important to pay attention to factors that could enhance usage of the program (first visit, staying on the website, revisits).Patients input, in combination with attention to dissemination, reach, adoption and implementation (emphasized in diffusion theory or RE-AIM theory), could be used to identify factors $[45,46]$. Moreover, qualitative research to explore the reasons for low usage should be conducted.

Fourth, to embed the program in regular health care, it is important that patient needs are also recognized by their rheumatologists or specialized rheumatology nurse and be used as a starting point during consultation. Nurses could also assist patients in performing exercises mentioned in the program, reminding patients to $\log$ on to the website and encourage patients to maintain their self-management behavior. Fifth, to increase the usage and efficacy of the program, a specific patient selection is needed. Further research is needed to assess which patient characteristics influence the use of a Web-based program and the outcomes, for example, by performing subgroup analysis among groups with a low or high functional disability or by assessing their level of motivation to use the program. This can determine which inclusion criteria should be used to select patients likely to benefit most.

\section{Conclusions}

In conclusion, although there is external evidence in favor of the efficacy of Web-based self-management interventions $[14,15]$, it is not recommended to conduct a larger trial yet. As advised by the MRC framework, a detailed process evaluation of the program should be conducted to gain thorough insight into the implementation of the program, the working elements of the program and the usage of the program by patients, which could be both important conditions for the success of a self-management program. This could also satisfy the need for attention to the usage and the perceived impact of the program to find out for whom this sort of program will work [47].

\section{Acknowledgments}

The authors would like to thank the RA patients and Valesca Hulsman for her help with translating the RASE questionnaire.

\section{Conflicts of Interest}

None declared.

\section{Multimedia Appendix 1 \\ CONSORT-eHEALTH checklist (V 1.6.1). \\ [PDF File (Adobe PDF File), 38MB-Multimedia Appendix 1]}

\section{References}

1. Hannan M. Epidemiologic perspectives on women and arthritis: an overview. Arthritis Care Res 1996 Dec;9(6):424-434. [doi: 10.1002/art.1790090603] [Medline: 9136285]

2. Sarzi-Puttini P, Salaffi F, di Franco M, Bazzichi L, Cassisi G, Casale R, et al. Pain in rheumatoid arthritis: a critical review. Reumatismo 2014 Jun 6;66(1):18-27 [FREE Full text] [doi: 10.4081/reumatismo.2014.760] [Medline: 24938192]

3. Repping-Wuts H, Uitterhoeve R, van Riel P, van Achterberg T. Fatigue as experienced by patients with rheumatoid arthritis (RA): a qualitative study. Int J Nurs Stud 2008 Jul;45(7):995-1002. [doi: 10.1016/j.ijnurstu.2007.06.007] [Medline: 17662291]

4. Repping-Wuts H, Fransen J, van Achterberg T, Bleijenberg G, van Riel P. Persistent severe fatigue in patients with rheumatoid arthritis. J Clin Nurs 2007 Nov;16(11C):377-383. [doi: 10.1111/j.1365-2702.2007.02082.x] [Medline: 17931330]

5. ter Wee MM, Lems WF, Usan H, Gulpen A, Boonen A. The effect of biological agents on work participation in rheumatoid arthritis patients: a systematic review. Ann Rheum Dis 2012 Feb;71(2):161-171. [doi: 10.1136/ard.2011.154583] [Medline: 21998122]

6. Connolly D, Fitzpatrick C, O'Toole L, Doran M, O'Shea F. Impact of fatigue in rheumatic diseases in the work environment: a qualitative study. Int J Environ Res Public Health 2015;12(11):a. [doi: 10.3390/ijerph121113807] [Medline: 26516896]

7. Wikstrom I, Isacsson A, Jacobsson LT. Leisure activities in rheumatoid arthritis: change after disease onsetassociated factors. Br J Occup Ther 2001;2(64):87-92. [doi: 10.1177/030802260106400206]

8. Giorgino KB, Blalock SJ, DeVellis RF, DeVellis BM, Keefe FJ, Jordan JM. Appraisal of and coping with arthritis-related problems in household activities, leisure activities, and pain management. Arthritis Care Res 1994 Mar;7(1):20-28. [doi: 10.1002/art.1790070106] [Medline: 7918722]

9. MacKinnon J, Avison W, McCain G. Pain and functional limitations in individuals with rheumatoid arthritis. Int J Rehabil Res 1994 Mar;17(1):49-59. [Medline: 7960328] 
10. Nichol M, Zhang L. Depression and health-related quality of life in patients with rheumatoid arthritis. Expert Rev Pharmacoecon Outcomes Res 2005 Oct;5(5):645-653. [doi: 10.1586/14737167.5.5.645] [Medline: 19807590]

11. Radford S, Carr M, Hehir M, Davis B, Robertson L, Cockshott Z, et al. 'It's quite hard to grasp the enormity of it': perceived needs of people upon diagnosis of rheumatoid arthritis. Musculoskeletal Care 2008 Sep;6(3):155-167. [doi: 10.1002/msc.132] [Medline: 18649347$]$

12. Berger M, Wagner TH, Baker LC. Internet use and stigmatized illness. Soc Sci Med 2005 Oct;61(8):1821-1827. [doi: 10.1016/j.socscimed.2005.03.025] [Medline: 16029778]

13. Atkinson NL, Gol RS. The promise and challenge of eHealth interventions. Am J Health Beh 2002;26(6):494-503. [doi: 10.5993/AJHB.26.6.10] [Medline: 12437024]

14. Lorig KR, Ritter PL, Laurent DD, Plant K. The internet-based arthritis self-management program: a one-year randomized trial for patients with arthritis or fibromyalgia. Arthritis Rheum 2008 Jul 15;59(7):1009-1017 [FREE Full text] [doi: 10.1002/art.23817] [Medline: 18576310]

15. Warsi A, Wang PS, LaValley MP, Avorn J, Solomon DH. Self-management education programs in chronic disease: a systematic review and methodological critique of the literature. Arch Intern Med 2004;164(15):1641-1649. [doi: 10.1001/archinte.164.15.1641] [Medline: 15302634]

16. Lorig K, González VM, Laurent D, Morgan L, Laris B. Arthritis self-management program variations: three studies. Arthritis Care Res 1998 Dec;11(6):448-454. [doi: 10.1002/art.1790110604] [Medline: 10030176]

17. Stinson J, McGrath PJ, Hodnett ED, Feldman BM, Duffy CM, Huber AM, et al. An internet-based self-management program with telephone support for adolescents with arthritis: a pilot randomized controlled trial. J Rheumatol 2010 Sep;37(9):1944-1952. [doi: 10.3899/jrheum.091327] [Medline: 20595280]

18. Or C, Karsh BT. A systematic review of patient acceptance of consumer health information technology. J Am Med Inform Assoc 2009;16(4):550-560 [FREE Full text] [doi: 10.1197/jamia.M2888] [Medline: 19390112]

19. van der Vaart R, Drossaert CH, Taal E, van de Laar MA. Patient preferences for a hospital-based rheumatology Interactive Health Communication Application and factors associated with these preferences. Rheumatology (Oxford) 2011 Sep;50(9):1618-1626. [doi: 10.1093/rheumatology/ker161] [Medline: 21551221]

20. Zuidema R, van Gaal GB, van Dulmen S, Repping-Wuts H, Schoonhoven L. An online tailored self-management program for patients with rheumatoid arthritis: a developmental study. JMIR Res Protoc 2015;4(4):a. [doi: 10.1080/13548500410001721855] [Medline: 26706653]

21. Bartholomew LK, Parcel GS, Kok G. Intervention mapping: a process for developing theory- and evidence-based health education programs. Health Educ Behav 1998;25(5):545-563. [doi: 10.1177/109019819802500502] [Medline: 9768376]

22. Kok G, Schaalma H, Ruiter RA, van Empelen P, Brug J. Intervention mapping: protocol for applying health psychology theory to prevention programmes. J Health Psychol 2004 Jan;9(1):85-98. [doi: 10.1177/1359105304038379] [Medline: $14683571]$

23. Craig P, Dieppe P, Macintyre S, Michie S, Nazareth I, Petticrew M. Developing and evaluating complex interventions: the new Medical Research Council guidance. Int J Nurs Stud 2013;50(5):587-592. [doi: 10.1016/j.ijnurstu.2012.09.010] [Medline: 18824488]

24. Zuidema R, Repping-Wuts H, Evers AW, Van Gaal BG, Van Achterberg T. What do we know about rheumatoid arthritis patients' support needs for self-management? A scoping review. Int J Nurs Stud 2015 Oct;52(10):1617-1624. [doi: 10.1016/j.ijnurstu.2015.05.008] [Medline: 26117711]

25. Ajzen I. The theory of planned behavior. Organizational Behavior and Human Decision Processes 1991 Dec;50(2):179-211 [FREE Full text] [doi: 10.1016/0749-5978(91)90020-T]

26. Abraham C, Michie S. A taxonomy of behavior change techniques used in interventions. Health Psychol 2008 May;27(3):379-387. [doi: 10.1037/0278-6133.27.3.379] [Medline: 18624603]

27. Uhlig T, Haavardsholm EA, Kvien TK. Comparison of the Health Assessment Questionnaire (HAQ) and the modified HAQ (MHAQ) in patients with rheumatoid arthritis. Rheumatology (Oxford) 2006 Apr;45(4):454-458. [doi: 10.1093/rheumatology/kei181] [Medline: 16287925]

28. Hibbard JH, Mahoney ER, Stockard J, Tusler M. Development and testing of a short form of the patient activation measure. Health Serv Res 2005 Dec;40(6 Pt 1):1918-1930 [FREE Full text] [doi: 10.1111/j.1475-6773.2005.00438.x] [Medline: 16336556]

29. Cramm J, Strating M, de Vreede VP, Steverink N, Nieboer A. Validation of the self-management ability scale (SMAS) and development and validation of a shorter scale (SMAS-S) among older patients shortly after hospitalisation. Health Qual Life Outcomes 2012;10:9. [doi: 10.1186/1477-7525-10-9]

30. Hewlett S, Cockshott Z, Kirwan J, Barrett J, Stamp J, Haslock I. Development and validation of a self-efficacy scale for use in British patients with rheumatoid arthritis (RASE). Rheumatology (Oxford) 2001;40(11):1221-1230. [doi: 10.1093/rheumatology/40.11.1221] [Medline: 11709605]

31. ten Klooster PM, Oostveen J, Zandbelt L, Taal E, Drossaert C, Harmsen E, et al. Further validation of the 5-item Perceived Efficacy in Patient-Physician Interactions (PEPPI-5) scale in patients with osteoarthritis. Patient Educ Couns 2012 Apr;87(1):125-130. [doi: 10.1016/j.pec.2011.07.017] [Medline: 21889864] 
32. Vander Zee KI, Sanderman R, Heyink JW, de Haes H. Psychometric qualities of the RAND 36-Item Health Survey 1.0: a multidimensional measure of general health status. Int J Behav Med 1996;3(2):104-122. [doi: 10.1207/s15327558ijbm0302 2] [Medline: 16250758]

33. Kraaimaat FW, Evers AW. Pain-coping strategies in chronic pain patients: psychometric characteristics of the pain-coping inventory (PCI). Int J Behav Med 2003;10(4):343-363. [doi: 10.1207/S15327558ijbm1004 5] [Medline: 14734263]

34. Arain M, Campbell M, Cooper C, Lancaster G. What is a pilot or feasibility study? A review of current practice and editorial policy. BMC Med Res Methodol 2010 Jul 16;10:67 [FREE Full text] [doi: 10.1186/1471-2288-10-67] [Medline: 20637084]

35. Lorig K, Sobel D, Ritter P, Laurent D, Hobbs M. Effect of a self-management program on patients with chronic disease. Eff Clin Pract 2001;4(6):256-262. [Medline: 11769298]

36. Cohen J, Cohen P, West S, Aiken L. Applied Multiple Regression/Correlation Analysis For The Behavioral Sciences Third Edition. New Jersey: Routledge; 2019.

37. Webb T, Joseph J, Yardley L, Michie S. Using the internet to promote health behavior change: a systematic review and meta-analysis of the impact of theoretical basis, use of behavior change techniques, and mode of delivery on efficacy. $\mathrm{J}$ Med Internet Res 2010 Feb 17;12(1):e4 [FREE Full text] [doi: 10.2196/jmir.1376] [Medline: 20164043]

38. Bartholomew L. Planning Health Promotion Programs: An Intervention Mapping Approach. San Francisco: Jossey-Bass; 2006.

39. Trappenburg J, Jonkman N, Jaarsma T, van Os-Medendorp H, Kort H, de Wit N, et al. Self-management: one size does not fit all. Patient Educ Couns 2013;92(1):134-137. [doi: 10.1016/j.pec.2013.02.009]

40. Crutzen R, Viechtbauer W, Spigt W, Kotz D. Differential attrition in health behaviour change trials: a systematic review and meta-analysis. Psychol Health 2015 Jan;30(1):122-134. [doi: 10.1080/08870446.2014.953526] [Medline: 25109224]

41. Brouwer W, Kroeze W, Crutzen R, de Nooijer N, de Vries NK, Brug J, et al. Which intervention characteristics are related to more exposure to internet-delivered healthy lifestyle promotion interventions? A systematic review. J Med Internet Res 2011 Jan 6;13(1):e2 [FREE Full text] [doi: 10.2196/jmir.1639] [Medline: 21212045]

42. Crutzen R, Viechtbauer W, Kotz D, Spigt M. No differential attrition was found in randomized controlled trials published in general medical journals: a meta-analysis. J Clin Epidemiol 2013 Sep;66(9):948-954. [doi: 10.1016/j.jclinepi.2013.03.019] [Medline: 23790724]

43. Andersson G, Cuijpers P. Internet-based and other computerized psychological treatments for adult depression: a meta-analysis. Cogn Behav Ther 2009;38(4):196-205. [doi: 10.1080/16506070903318960] [Medline: 20183695]

44. Hurn J, Kneebone I, Cropley M. Goal setting as an outcome measure: a systematic review. Clin Rehabil 2006 Sep;20(9):756-772. [doi: 10.1177/0269215506070793] [Medline: 17005500]

45. Glasgow RE, Vogt TM, Boles SM. Evaluating the public health impact of health promotion interventions: the RE-AIM framework. Am J Public Health 1999;89(9):1322-1327. [doi: 10.2105/AJPH.89.9.1322] [Medline: 10474547]

46. Rogers EM. Diffusion of Innovations. New York: Simon \& Schuster; 2003.

47. Campbell N, Murray E, Darbyshire J, Emery J, Farmer A, Griffiths F, et al. Designing and evaluating complex interventions to improve health care. Br Med J 2007 Mar 3;334(7591):455-459 [FREE Full text] [doi: 10.1136/bmj.39108.379965.BE] [Medline: 17332585$]$

\author{
Abbreviations \\ IM: intervention mapping \\ M-HAQ: Modified Health Assessment Questionnaire \\ MPCI-F: Modified Pain Coping Inventory for Fatigue \\ MRC: Medical Research Council \\ NRS: Numeric Rating Scale \\ PAM-13: Patient Activation Measurement \\ RA: rheumatoid arthritis \\ RASE: Rheumatoid Arthritis task-specific Self-Efficacy Questionnaire \\ RCT: randomized controlled trial \\ SMAS-S: Short Self-Management Ability Scale
}


Edited by G Eysenbach; submitted 12.10.18; peer-reviewed by P van Riel, C Varsi; comments to author 11.11.18; revised version received 29.11.18; accepted 29.11.18; published 30.04.19

Please cite as:

Zuidema R, van Dulmen S, Nijhuis-van der Sanden M, Meek I, van den Ende C, Fransen J, van Gaal B

Efficacy of a Web-Based Self-Management Enhancing Program for Patients with Rheumatoid Arthritis: Explorative Randomized Controlled Trial

J Med Internet Res 2019;21(4):e12463

URL: https://www.jmir.org/2019/4/e12463/

doi: $\frac{10.2196 / 12463}{P: 3103861}$

PMID: 31038461

CRixt Zuidema, Sandra van Dulmen, Maria Nijhuis-van der Sanden, Inger Meek, Cornelia van den Ende, Jaap Fransen, Betsie van Gaal. Originally published in the Journal of Medical Internet Research (http://www.jmir.org), 30.04.2019. This is an open-access article distributed under the terms of the Creative Commons Attribution License (https://creativecommons.org/licenses/by/4.0/), which permits unrestricted use, distribution, and reproduction in any medium, provided the original work, first published in the Journal of Medical Internet Research, is properly cited. The complete bibliographic information, a link to the original publication on http://www.jmir.org/, as well as this copyright and license information must be included. 